\title{
Estudio de la transtextualidad en el cine de Quentin Tarantino*
}

Fecha de recepción: 02 de marzo de 2021

Fecha de aprobación: 24 de mayo de 2021

\section{Resumen}

El cine y la literatura tienen amplias e importantes relaciones prácticas y teóricas. En relación con las últimas, la teoría de la transtextualidad, creada por Gérard Genette, ha jugado un rol fundamental, debido al vasto número de referencias que se han hecho de obras audiovisuales o literarias en otros filmes. En virtud de lo anterior, aplicamos los tipos de transtextualidades de Genette - junto con las nociones cinematográficas creadas por Robert Stam y otros teóricos partiendo de sus postulados - para analizar y ejemplificar algunas de las relaciones transtextuales más notorias en la filmografía de Quentin Tarantino, realizador notorio actualmente en este campo. Por tanto, encontramos que existe una gran y especial cantidad de conexiones transtextuales en sus largometrajes, lo cual resulta importante para demostrar la relevancia de esto en su autoría y en la mencionada relación entre la literatura y el cine.

Palabras clave: análisis fílmico y cinematográfico, Gérard Genette, intertextualidad, Quentin Tarantino, transtextualidad.

Citar: Dumont, Gabriel. "Estudio de la transtextualidad en el cine de Quentin Taratino". La Palabra, num.40, 2021, e12542. Gihttps://doi. org/10.19053/01218530.n40.2021.12542

\section{Gabriel Dumont}

Licenciado en Artes, mención Artes Cinematográficas por la Universidad Central de Venezuela (UCV). Fue asistente de investigación del Instituto de Investigaciones de la Comunicación ININCO-UCV, en cuyo Anuario ha publicado dos artículos de investigación. Se desempeñó como profesor de las cátedras Cinematografía I y II en la Escuela de Artes de la UCV y de Historia del Cine II de la Escuela Nacional de Cine (ENC). Coordinó el Diplomado en Dirección Cinematográfica de la ENC y fue profesor del módulo de Análisis Cinematográfico del mismo. gabrieldg070893@gmail.com

(D)https://orcid.org/000000027571-4513

* Artículo de reflexión. Este se desarrolla a partir del trabajo especial de grado (TEG) Beatrix Kiddo en el viejo Oeste. Influencia narrativa, estilística $y$ transtextual del western en los filmes Kill Bill vol. 1 y Kill Bill vol. 2. 


\title{
Study of transtextuality in the cinema of Quentin Tarantino
}

\begin{abstract}
Cinema and literature have broad and important practical and theoretical relationships. In relation to the latter, the theory of transtextuality, created by Gérard Genette, has played a fundamental role, due to the vast number of references that have been made to audiovisual or literary works in other films.By virtue of the former, we apply Genette's types of transtextualities along with the cinematographic notions created by Robert Stam and other theorists based on his postulates to analyze and exemplify some of the most notorious transtextual relationships in Quentin Tarantino's filmography, currently notorious filmmaker in this field. Therefore, we find that there is a large and special amount of transtextual connections in his films, which is important to demonstrate the relevance of this in his authorship and in the aforementioned relationship between literature and cinema.
\end{abstract}

Key words: filmic and cinematographic analysis, Gerard Genette, intertextuality, Quentin

\section{Estudo da transtextualidade no cinema de Quentin Tarantino}

\section{Resumo}

O cinema e a literatura têm amplas e importantes relações práticas e teóricas. Em relação a essas últimas, a teoria da transtextualidade, criada por Gérard Genette, tem tido um papel fundamental, dado o extenso número de referências feitas sobre obras audiovisuais e literárias em outros filmes. Nesta área, Quentin Tarantino é o realizador mais renomado na atualidade, graças às múltiplas e especiais conexões transtextuais que faz nas suas longametragens. Portanto, aplicamos os tipos de transtextualidade expostos por Genette junto às noções cinematográficas de Robert Stam e outros teóricos a partir dos seus postulados para estudar e exemplificar algumas das mais notórias na filmografia de Tarantino, e demostrar a importância disto na sua autoria e na nomeada relação entre a literatura e o cinema.

Palavras-chave: análise fílmica e cinematográfica, Gérard Genette, intertextualidade, Quentin Tarantino, transtextualidade. 
La literatura y el cine tienen una gran cantidad de puntos de encuentro, que se remontan casi hasta la invención del mismo cine. Los lenguajes literarios y cinematográficos hacen uso de manera similar de temáticas diversas y bien delimitadas; de unidades estructurales como la clásica aristotélica, por ejemplo; de los amplios recursos narrativos como los tipos de narradores, las unidades semánticas y las formas sintácticas y la extensión del relato, entre otros; y el uso de formas estilísticas que, sumado a todo lo anterior, le provee a las obras literarias y cinematográficas de sus características genéricas.

Esta correlación entre un arte y otro ha propiciado no solo el encuentro de la práctica, sino también de la teoría y el análisis, como lo han demostrado investigadores y teóricos como Christian Metz, Jacques Aumont o Siegfried Kracauer. Las teorías sobre los géneros narrativos y cinematográficos, el análisis narratológico, los estudios sobre adaptaciones fílmicas o la transtextualidad (también denominada intertextualidad, dependiendo del autor) son ejemplos importantes de este intercambio teórico.

Precisamente, el estudio transtextual está adquiriendo gran relevancia para el saber del cine en la actualidad, puesto que una extensa cantidad de realizadores hacen conexiones en sus filmes de otras producciones fílmicas y televisivas, así como de novelas, cómics y obras de teatro. Este es el caso del director Quentin Tarantino, quien, entre tantos aspectos, se destaca por hacer citas y alusiones constantes de sus filmes, series y demás productos predilectos de la cultura popular, dentro de sus propios filmes.

Por lo tanto, se empleará la teoría de la transtextualidad, creada por Gérard Genette e inspirada por los estudios de Mijaíl Bajtín y, sobre todo, de Julia Kristeva, además de la ampliación teórica hecha por Robert Stam, Robert Burgoyne y Sandy Flitterman-Lewis, elaborada para los estudios del cine, para estudiar cómo Tarantino aprovecha las diversas relaciones transtextuales en su filmografía y, en última instancia, demostrar por qué esto es un aspecto vital de su estilo autoral fílmico.

\section{Del dialogismo de Mijaíl Bajtín a la transtextualidad de Gérard Genette}

La teoría de la «transtextualidad», elaborada por Gérard Genette (1989), tiene sus antecedentes en otros dos postulados de gran importancia dentro de los estudios lingüísticos y literarios: ${ }^{1}$ el «dialogismo», desarrollado por Mijaíl Bajtín, y la «intertextualidad», escrito por Julia Kristeva ${ }^{2}$.

Bajtín, tomando como referencia la obra de Fiódor Dostoievski, define el «dialogismo» como «la relación necesaria de cualquier expresión con otras expresiones» (Stam, Burgoyne y Flitterman-Lewis) ${ }^{3}$, y que, a su vez, tiene sus raíces morfológicas y conceptuales en el término «diálogo» (232). Bajtín explica que el «dialogismo» se da en las novelas de Dostoievski

Debemos acotar que esta rama teórica también es relevante dentro de otras formas artísticas (cine, teatro, pintura, etc.). Es importante mencionar que Bajtín, Kristeva y Genette publicaron sus estudios en 1929, 1967 y 1982, respectivamente. No obstante, las fechas referidas en el artículo pertenecen a las ediciones de sus libros empleados para la investigación. Stam, Burgoyne y Flitterman-Lewis aclaran que, para Bajtín, el término expresión abarca desde un conjunto de signos hasta una obra compleja y amplia (novela, película, etc.). 
porque son polifónicas, es decir, que parecen estar construidas por diversas voces. Específicamente, poseen características comunes (el diálogo como acción; el misterio como género principal sobre todo en sus últimos textos, por ejemplo) y hasta discordantes (la pluralidad de ideologías que resultan contradictorias, inclusive), que además le confieren a toda su obra sus propios atributos de calidad y rasgos autorales (Bajtín 15-19).

En esta interacción entre «expresiones» también es fundamental la «heteroglosia», término acuñado por Bajtín y conceptualizado por Narcisa García como:

interacción entre dialectos y jergas que tiene como resultado un idioma. Es decir, se trata de una comunicación entre textos a través de sus enunciados, que supone el conocimiento previo por parte del lector de otros textos contenidos en el texto presente (García 7).

En otras palabras, una «expresión» puede ser producto de la relación entre dos o más «expresiones», y el resultado ser tácito o explícito. Para que el lector entienda cómo está compuesta la expresión final en su totalidad, debe conocer las expresiones primigenias, como sería un diálogo.

En los casi incontables ejemplos ofrecidos por la literatura del dialogismo, uno de ellos lo encontramos en la obra Diálogos escrita por Platón. El Hipias mayor o de lo bello (uno de estos diálogos) demuestra cómo el intercambio de ideas entre Sócrates e Hipias deriva en un conocimiento más amplio y de interés mutuo, siendo evidente, además, cuáles pensamientos pertenecen a cada filósofo (Dumont 69).

En el texto «Bajtín, la palabra, el diálogo y la novela», Kristeva apoya y sustenta todo lo anterior al argumentar que:

Bajtín es uno de los primeros en sustituir la segmentación estática de los textos por un modelo en que la estructura literaria no es, sino que se elabora con respecto a otra estructura. Esta dinamización del estructuralismo sólo es posible a partir de una concepción según la cual la "palabra literaria" no es un punto (un sentido fijo), sino un cruce de superficialidades textuales, un diálogo de varias escrituras [...] (Kristeva 2).

De esta forma, Kristeva -inspirada por los axiomas de Bajtín y enmarcándose en la semiótica- presenta la «intertextualidad» un poco más desarrollada en determinados aspectos que el propio «dialogismo». Este concepto se define por lo siguiente:

[...] todo texto se construye como mosaico de citas, todo texto es absorción y transformación de otro texto. En el lugar de la noción de intersubjetividad se instala la de intertextualidad, y el lenguaje poético se lee, por lo menos, como doble (Kristeva 3).

Similar a Bajtín, Kristeva argumenta que un «texto» es una construcción que parte de otro texto. Sin embargo, a diferencia del primero, Kristeva introduce el término «cita» (entendido como un extracto literal de un texto contenido en otro), con lo cual especifica una práctica común en el ejercicio «intertextual»; y, por último, hace alusión a la lectura doble de 
un texto, ya que es posible estudiarlo por cómo es y, también, por cómo es posible que haya sido anteriormente o, mejor dicho, por sus principales influencias.

Consideraremos también el término «ideologema», definido como «función intertextual que se puede leer "materializada" en los diferentes niveles de la estructura de cada texto, y que se extiende a todo lo largo de su trayecto dándole sus coordenadas históricas y sociales» (Kristeva 148).

Parafraseando a Iván Villalobos Alpízar, el «ideologema» expone que los «textos» obtienen determinadas características por el tiempo, el espacio y la cultura en el que se producen; en efecto, esto significa que existe una gran probabilidad de que un texto «tome» aspectos de otro análogo a su cultura o de una afín $(143)^{4}$. En síntesis, Villalobos Alpízar apunta a que «el ideologema es, entonces, la función que une las prácticas translingüísticas de una sociedad, condensando el modo dominante de pensamiento» (143). La novela Frankenstein o el moderno Prometeo (Frankenstein or The Modern Prometheus, publicada originalmente en 1818), escrita por Mary Shelley (2011), ejemplifica lo expuesto sobre la «intertextualidad»:

- Se inspira temáticamente en el mito griego de Prometeo (inclusive, el título hace referencia a él) y la obra El paraíso perdido (Paradise Lost, 1975), de John Milton; incluso, Shelley cita al inicio un extracto de esta última: «¿Acaso te pedí, hacedor mío, que de mi barro moldearas a un hombre? ¿Solicité de ti que de la oscuridad me ascendieras?» ( 73).

- $\quad$ Aunque es factible estudiar Frankenstein o el moderno Prometeo por sí sola, también podría estudiarse en relación con el referido mito griego y el poema narrativo de Milton, como bien lo demostraron Román Gubern y Joan Prat (1979). De esta forma, se cumple la posible lectura doble.

- En cuanto al «ideologema», es notable que Shelley se inspiró, en un principio, en dos relatos europeos, a pesar de que uno pertenezca a la antigüedad griega y el otro, aunque fue publicado en Londres al igual que su novela, haya sido presentado originalmente 151 años antes que la obra de Shelley, concretamente en 1667.

Como mencionamos al inicio, las teorías de Bajtín y Kristeva fueron relevantes para el desarrollo de la «transtextualidad» (o «trascendencia textual») de Genette, pero esta es más extensa y detallada. Genette define la «transtextualidad» como «todo lo que pone al texto en relación, manifiesta o secreta, con otros textos» (Genette 9-10), y divide las relaciones «transtextuales» en cinco tipos concretos y bastante diferenciados. El primero es la «intertextualidad» (apelando al trabajo de Kristeva, evidentemente), que define y divide en tres subtipos de la siguiente manera:

[es la] relación de copresencia entre dos o más textos, es decir, eidéticamente y frecuentemente, como la presencia efectiva de un texto en otro. Su forma más explícita y literal es la

4 Si bien esto es una práctica recurrente a lo largo de la historia de la literatura y del arte, en general, en cuantiosas oportunidades no ha sido así. Más adelante ofreceremos algunos ejemplos enmarcados en el cine. 
práctica tradicional de la cita (con comillas, con o sin referencia precisa); en una forma menos explícita y menos canónica, el plagio [...] que es una copia no declarada pero literal; en forma todavía menos explícita y menos literal, la alusión, es decir, un enunciado cuya plena comprensión supone la percepción de su relación con otro enunciado al que remite necesariamente tal o cual de sus inflexiones [...] (Genette 10).

Del primer subtipo tenemos una cita textual hecha por John Kennedy Toole, en su novela La conjura de los necios (A Confederacy of Dunces, 2011) ${ }^{5}$, del ensayo Thoughts on Various Subjects, Moral and Diverting, escrito por Jonathan Swift, y del cual parece inspirarse para el título de su obra: «Cuando en el mundo aparece un verdadero genio, puede identificarse por este signo: todos los necios se conjuran contra él» (Kennedy Toole 7).

Del segundo y controversial subtipo ${ }^{6}$, Alvin Kernan (1996) reseña el caso de la novela The White Hotel, escrita por D. M. Thomas, y el libro Babi Yar, de Anatoli Kuznetsov. De acuerdo con Kernan, Thomas plagió literalmente (o con ligeros cambios en determinadas partes) la entrevista de la actriz Dina Pronicheva en Babi Yar, para describir los terribles hechos de la matanza del pueblo homónimo a manos de los nazis.

La primera edición de The White Hotel reconoce cierta deuda con Kuznetsov y Dina Pronicheva en la página del copyright aunque en un tipo muy pequeño: «También reconozco con agradecimiento el uso en la Parte V de material de Babi Yar de Kuznetsov y en particular el testimonio de Dina Pronicheva». La palabra 'uso' da la sensación de un circunloquio, sobre todo si se nota en el mismo párrafo el reconocimiento pleno de la cita que el patrimonio Yeats exigió para unos cuantos versos. [...]

Para decirlo llanamente, Thomas a fin de cuentas ocultó que se había copiado letra por letra al menos cuatro o cinco páginas, de Pronicheva y Kuznetsov, lo cual rebasa con mucho lo que cualquier corte de justicia hasta ahora ha permitido con la cláusula del «uso justo». [...]

El caso habría resultado menos grave si Thomas hubiese puesto entre comillas el material que tomó o si hubiese reconocido pública y específicamente que está citando a Kuznetsov, y en qué medida, o si le hubiese pedido permiso, cosa que nunca hizo, a los editores o al autor para citar el material que imprimió (Kernan 115-117).

En relación con el tercer subtipo, tenemos que la temática y narrativa de la trilogía de $E l$ señor de los anillos (The Lord of the Rings de J. R. R. Tolkien), están construidas en parte con alusiones y referencias a diversos mitos nórdicos (como el del anillo del nibelungo) y, sobre todo, a Beowulf, célebre poema épico germánico del siglo VIII (Colbert 33-39). En efecto, Tolkien no cita en sus novelas ningún extracto de otras obras, pero sí es claro, para el lector que conoce la mitología y el poema referidos, cuáles son las alusiones que hizo de ellos?

Inicialmente, La conjura de los necios se publicó en 1980; para la presente investigación empleamos la edición de 2011. Decimos controversial porque si bien es una copia textual de un extracto de un texto, esta es ilegal por no declararse de ninguna forma o de manera velada, como bien acota Genette.

Tolkien además dejó claro en diversas correspondencias y entrevistas la influencia que tuvo Beowulf y los mitos nórdicos en toda su obra. 
La segunda relación transtextual es la «paratextualidad», definida y detallada como:

El segundo tipo está constituido por la relación, generalmente menos explícita y más distante, que, en el todo formado por una obra literaria, el texto propiamente dicho mantiene con lo que solo podemos nombrar como su paratexto: título, subtítulo, intertítulos, prefacios, epílogos, advertencias, prólogos, etc.; notas al margen, a pie de página, finales; epígrafes; ilustraciones; fajas; sobrecubierta, y muchos otros tipos de señales accesorias, autógrafas o alógrafas, que procuran un entorno (variable) al texto [...] (Genette 11).

Un ejemplo de este tipo está en el prólogo que escribió Aldous Huxley para su novela $U n$ mundo feliz (Brave New World), en el cual aborda de manera breve el contexto histórico de su distopía, entre otros aspectos; asimismo, Huxley escribió otro «paratexto» titulado Nueva visita a un mundo feliz (Brave New World Revisited), que es un estudio más profundo de las temáticas e influencias de su novela (Dumont 74).

El tercer tipo es la «metatextualidad», conceptualizada como «la relación — generalmente denominada "comentario"- que une un texto a otro texto que habla de él sin citarlo (convocarlo), e incluso, en el límite sin nombrarlo. [...] La metatextualidad es por excelencia la relación crítica» (13). Verbigracia, en La cultura. Todo lo que hay que saber (Bildung. Alles, was man wissen muss, 2003), Dietrich Schwanitz crítica diversas obras literarias del canon europeo como La Divina comedia (The Divine Comedy, Dante Alighieri), Don Quijote de la Mancha (Miguel de Cervantes), Robinson Crusoe (Daniel Defoe) y Guerra y paz (Voyna $i$ mir, León Tolstói), para demostrar su importancia no solo dentro de la historia de la literatura y cultura europea, sino, también, para casi cualquier otra cultura del mundo.

La siguiente relación transtextual es la «hipertextualidad». Genette la describe y divide como:

toda relación que une un texto B (que llamaré hipertexto) a un texto anterior A (al que llamaré hipotexto) en el que se injerta de una manera que no es la del comentario. [...] Para decirlo de otro modo, tomemos una noción general de texto en segundo grado [...] o texto derivado de otro texto preexistente. Esta derivación puede ser del orden descriptivo o intelectual en el que un metatexto (digamos tal página de la Poética de Aristóteles) «habla» de un texto (Edipo Rey). Puede ser de orden distinto tal que B no hable en absoluto de A, pero que no podría existir sin A, del cual resulta al término de una operación que calificaré [...] como transformación, y al que, en consecuencia evoca más o menos explícitamente, sin necesariamente hablar de él y citarlo (Genette 13).

Además del ejemplo ofrecido por Genette del primer subtipo, consideraremos La sangre de los libros, en el que Santiago Posteguillo (2015) comenta someramente obras literarias como Drácula (Dracula, Bram Stoker) o Los asesinatos de la calle Morgue (The Murders in the Rue Morgue, Edgar Allan Poe), haciendo énfasis en sus tramas o hechos curiosos que las involucran, en vez de análisis y críticas de las mismas. Del segundo subtipo (que también podemos denominar «adaptación») tenemos la novela de no-ficción Treblinka (Jean-Françoise Steiner), adaptada a partir de las entrevistas y los testimonios escritos de los 40 sobrevivientes (de un grupo de 600) que lograron escapar del campo de exterminio nazi homónimo. En otras 
palabras, La sangre de los libros y Treblinka son - a sus propias maneras- los «hipertextos» de las mencionadas obras y testimonios, respectivamente, que serían los «hipotextos».

El último tipo de «transtextualidad» es la «architextualidad» que, parafraseando a Genette, ya se introdujo en el segundo tipo, y es definida de la siguiente forma:

Se trata de una relación completamente muda que, como máximo, articula una mención paratextual (títulos, como en Poesías, Ensayos, Le Roman de la Rose, etc., o, más generalmente, subtítulos: la indicación Novelas, Relato, Poemas, etc., que acompaña al título en la cubierta del libro), de pura pertenencia taxonómica. Cuando no hay ninguna mención, puede deberse al rechazo de subrayar una evidencia o, al contrario, para recusar o eludir cualquier clasificación. En todos los casos, el texto en sí mismo no está obligado a conocer, y mucho menos a declarar, su cualidad genérica (Genette 13).

Por ejemplo, en la recopilación de escritos Mecanismos internos. Ensayos 2000-2005 (Inner Workings, 2009), del escritor J. M. Coetzee, se deja claro en el título el género literario al que pertenece. De manera similar, en cuanto a los géneros de ficción:

Títulos de novelas como Asesinato en el Orient Express o El asesinato de Roger Ackroyd, ambas de Agatha Christie, refieren a los géneros [...] de crimen y misterio; diferente a lo visto en los libros Todo fluye de Vasili Grossman y El señor de las moscas de William Golding, cuyos títulos no remiten a un género específico, y en los cuales es probable que, como bien expresa Genette, se rechace una catalogación genérica (Dumont 76).

Finalmente, Robert Stam, Robert Burgoyne y Sandy Flitterman-Lewis acuñaron cinco «relaciones transtextuales» más, centrados en el paradigma de Genette, y relacionados principalmente con el cine; no obstante, es posible ejemplificarlos también con textos literarios. La primera de estas relaciones es la «intertextualidad de celebridades» definida como:

situaciones cinematográficas en las que la presencia de una estrella de cine o televisión o una celebridad intelectual evoca un género o un ambiente cultural (Truffaut en Encuentros en la tercera fase [Close encounters of the third kind, 1977], Norman Mailer en King Lear, de Godard, Marshall McLuhan en Annie Hall [Annie Hall, 1977]) (Stam et. al. 236).

A parte de los ejemplos ofrecidos por los mencionados autores, encontramos que una figura literaria reconocida como Stephen King, por ejemplo, evoca un género específico (terror, en este caso) con sus apariciones especiales en películas como Cementerio de mascotas (Pet Sematary, Mary Lambert, 1989) y Creepshow: El festín del terror (Creepshow, George A. Romero, 1982). Asimismo, la presencia de Salman Rushdie y Jeffrey Archer en la película El diario de Bridget Jones (Bridget Jones Diary, Sharon Maguire, 2001) también evoca un contexto cultural literario (Dumont 76).

La segunda relación transtextual es la «intertextualidad genética»; sucintamente, en palabras de los autores, se define por ser «[...] procesos mediante los cuales la aparición de 
los hijos y las hijas de actores y actrices famosos - Jamie Lee Curtis, Liza Minelli, Melanie Griffith-, evocan el recuerdo de sus famosos padres» (Stam et al 236).

El siguiente tipo es la «intratextualidad», conceptualizada como «[...] procesos mediante los que las películas se refieren a sí mismas mediante estructuras especulares, microcósmicas, y mise-en-abyme [...]» (Stam et al 236). Si bien los autores no mencionan ejemplos cinematográficos, podemos considerar el filme Frankenstein (James Whale, 1931), puesto que, al inicio, el actor Edward Van Sloan (quien interpreta al personaje del Dr. Waldman dentro de la diégesis $\left.{ }^{8}\right)$ se dirige a los espectadores advirtiéndoles sobre lo terrorífica que será la película (Dumont 77). En relación con la literatura, en la novela El túnel, escrita por Ernesto Sabato (2007), el protagonista, Juan Pablo Castel, deja claro al inicio que leeremos la historia que él escribió sobre su crimen, haciendo así la obra referencia a sí misma.

El cuarto tipo es la «autocita» que es «[...] la cita a cargo de un mismo autor, como cuando Vincente Minnelli cita su propia Cautivos del mal (The Bad and the Beautiful, 1952) dentro de Dos semanas en otra ciudad (Two Weeks in Another Town, 1962)» (Stam et al 236). Además de esto, el referido King cita en Mientras escribo (On Writing), su manual de escritura, a su ópera prima, Carrie; a su vez, aborda la historia del perro Cujo, protagonista de su novela homónima, en su otra novela sobre animales asesinos titulada Cementerio de animales (Pet Sematary) (Dumont 77).

Por último, Stam et al. apuntan y conceptualizan la «intertextualidad falsa» de la siguiente forma: «La intertextualidad falsa evocaría esos textos, por ejemplo los pseudonoticiarios de Zelig o la imitación de las películas nazis en El beso de la mujer araña, que crean una referencia pseudointertextual» (Stam et al 236).

En otras palabras, la «intertextualidad falsa» hace referencia a obras inexistentes o que solo existen dentro de otra obra. Un caso ejemplar es La literatura nazi en América, recopilación de biografías de autores y sus obras ficticias inexistentes escritas por Roberto Bolaño (Dumont, 27); también, dentro de la distopía 1984, de George Orwell (2012), existen extractos extensos del texto ficticio Teoría y práctica del colectivismo oligárquico (aparentemente escrito por Emmanuel Goldstein, enemigo acérrimo del Gran Hermano), y que expone el verdadero contenido de las doctrinas del partido fascista imperante en la diégesis.

8 El término diégesis hace referencia al universo espacio temporal ficticio en el cual se desarrolla una obra (película, novela, obra de teatro, etc.). 


\section{Transtextualidad en el cine de Quentin Tarantino}

En el ensayo Una cierta tendencia del cine francés (Une certaine tendance du cinema français), François Truffaut (Romaguera i Ramió y Alsina Thevenet, 1993) expuso -retomando a su vez los postulados de Alexander Astruc y André Bazin- que el «cine de autor», en contraposición a la despectivamente denominada «tradición de qualité», se identifica por tener impresa la «personalidad» del director a través de reminiscencias autobiográficas y, sobre todo, de su característico talante artístico.

La teoría del autor sostenía que los directores intrínsecamente fuertes exhiben con el paso de los años una personalidad estilística y temática reconocible, incluso en el marco de los estudios de Hollywood. Es decir, que el verdadero talento siempre «sale a la luz» sin importar las circunstancias (Stam 107).

Directores célebres como Stanley Kubrick, Alfred Hitchcock, Charles Chaplin, Luis Buñuel o Hayao Miyazaki ${ }^{9}$ son considerados unánimemente como realizadores que se inscriben dentro del cine de autor gracias a los temas, narrativas, y estilos visuales y sonoros de sus filmes. Y por supuesto, dentro de tan selecto grupo, también podemos incluir a Quentin Tarantino.

Este director posee un estilo particularisimo que alcanza varios de los oficios de la creación de películas: dirección, guión, música, dirección de fotografía, casting de actores, entre otros. Incluso, ya que emplea reiteradamente determinadas características, podemos esquematizar su estilo en los siguientes ítems:

- Diálogos extensos que abordan temas concernientes a la propia película o aparentemente ajenos a ella.

- Modificación de la cronología diegética.

- Violencia similar a la real o hiperbolizada.

- Uso del humor negro.

- Empleo de la venganza como tema central o secundario.

- Diversas conexiones entre sus propias películas.

- Uso constante de las distintas formas de «transtextualidad», relacionadas con películas, cómics, series televisivas y novelas (Dumont 80).

Si bien Stam hace énfasis en la industria hollywoodense, las obras de Buñuel y Miyazaki no se enmarcan en esta industria. 
Precisamente, el último punto es uno de los más comentados y estudiados sobre su filmografía ${ }^{10}$. Para empezar a entender cómo Tarantino trabaja en este aspecto, tomaremos la siguiente cavilación del escritor David L. Robbins, hecha para la introducción de la versión publicada del guión de Bastardos sin gloria:

Hace tiempo conocí a un chico como Quentin Tarantino. A los once años, Scott era un genio. Su especialidad no eran las imágenes ni el humor negro ni la historia ni nada propio de humanos. Era un fenómeno con las máquinas. Yo le daba al chaval aparatos electrónicos descompuestos y restos de tecnología estropeada, y él me devolvía una linterna hecha con un reproductor de ocho pistas, una tostadora fabricada con casetes o un radio despertador que había construido con piezas de tocadiscos. [...]

De manera parecida, a lo largo de su carrera cinematográfica, Quentin Tarantino ha construido a partir de lo cotidiano cosas nunca vistas antes. Su apreciación del statu quo del cine ha sido siempre la de un inventor que rebusca en una chatarrería. Una y otra vez ha escogido trozos del pasado, ha ensamblado por igual tradiciones y tópicos en formas que reconocemos sólo en fragmentos. Sus películas arden ante nuestra mirada y hace que se nos antojen extrañas y familiares, todo a la vez (Tarantino 7).

De esto podemos inferir lo siguiente: 1) con lo «cotidiano», Robbins se refiere, principalmente, a la cultura popular que impregna muchos aspectos de la vida en general, y es que, en efecto, Tarantino no discrimina ninguna forma cultural; 2) el uso de la palabra «chatarrería» no es casual, puesto que Tarantino prefiere hacer referencias y citas de películas estrenadas antes del decenio de 1990, especialmente de la década de 1960 y 1970, que no son tan conocidas por el público, o también pertenecientes al prolífico cine serie $\mathrm{B}$, muchas veces denostado por críticos y académicos; 3 ) así, tanto para quienes conocen las producciones de las cuales se inspira como quienes las desconocen, sus obras pueden resultar similares a otras o únicas por la variedad de combinaciones que hace; 4) por último, Tarantino no se limita a homenajear a otros filmes, sino que los usa para desarrollar sus propias temáticas, narrativas y estilo artístico. En relación con esto, Guillermo Cabrera Infante apuntó «El cine ha venido del teatro (necesidad de fotografiar actores y, desde la invención del vitafón, de oírlos) o de la novela (necesidad del prestigio de los libros). Es solamente ahora que el cine viene del cine» (456).

Por tanto, tomando el subtipo «cita» de la «intertextualidad» de Genette, si en la literatura sería un extracto de un texto contenido en otro, en el cine es un fragmento visual o sonoro de una película dentro de otra. Por ejemplo, en una escena de Había una vez en... Hollywood (Once Upon a Time... in Hollywood, 2019), el filme de Tarantino que más relaciones transtextuales hace de forma explícita, Sharon Tate (Margot Robbie) va al cine a ver su película Las demoledoras (The Wrecking Crew, Phil Karlson, 1968), de la cual se muestran algunas escenas reales. Esta escena no solo homenajea a la verdadera Tate y el mencionado filme,

$10 \quad$ ¿Por qué Tarantino hace con insistencia relaciones transtextuales de otros textos? Los motivos principales los podemos encontrar en su biografía, puesto que su madre, Connie McHugh, lo alentó desde pequeño a ver todo tipo de cine. También, Tarantino ha dejado claro en diversas entrevistas que nunca fue a una escuela de cine, sino que fue al cine, por tanto, su trabajo en el videoclub Video Archives contribuyó a su cinefilia (Dumont, 2017). 
sino que, también, funciona para resaltar el momento de satisfacción personal y laboral que tiene el personaje de Tate en la ficción.

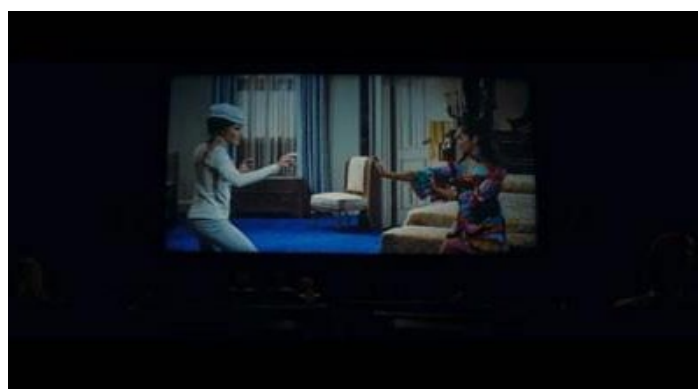

Figura 1. Proyección de Las demoledoras. Freya Carlson (Sharon Tate) pelea con Wen Yu-Rang (Nancy Kwan).

Fuente: fotograma extraído de la versión en DVD. Todos los derechos pertenecen a la productora Sony Pictures Entertainment.

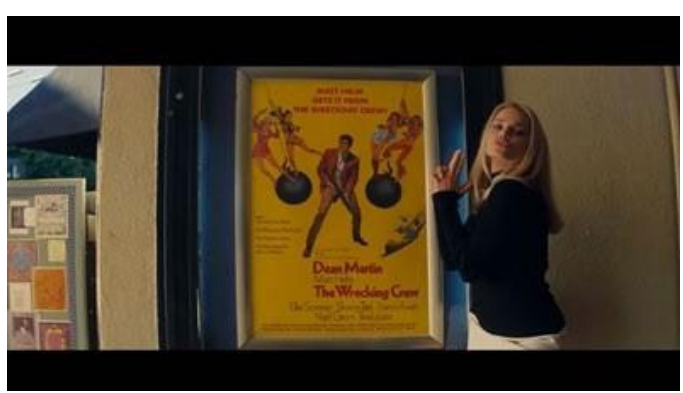

Figura 2. Sharon Tate (Margot Robbie) con un poster real de Las demoledoras.

Fuente: fotograma extraído de la versión en DVD. Todos los derechos pertenecen a la productora Sony Pictures Entertainment

Otra cita está en Pulp Fiction (Quentin Tarantino, 1994), en la escena en que Fabienne (Maria de Medeiros), la novia de Butch Coolidge (Bruce Willis), está viendo la película Los perdedores (The Losers, Jack Starrett, 1970); lo llamativo de esta cita es que el reflejo de Fabienne está «dentro» de la balacera que observamos en la televisión, como una advertencia para el espectador de lo que sucederá en las violentas escenas siguientes.

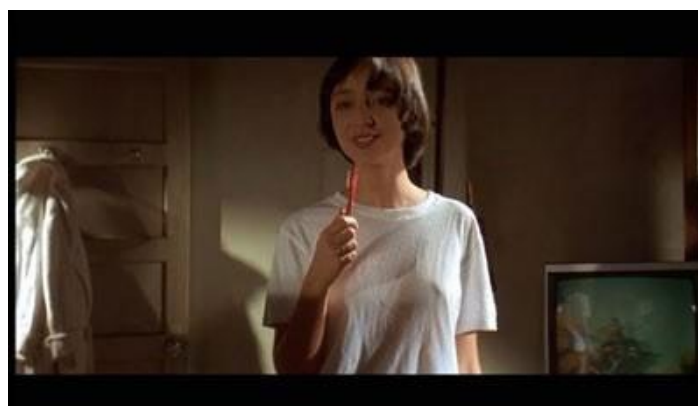

Figura 3. Fabienne (María de Medeiros) se cepilla los dientes mientras mira Los perdedores.

Fuente: fotograma extraído de la versión en DVD. Todos los derechos pertenecen a la productora Miramax.

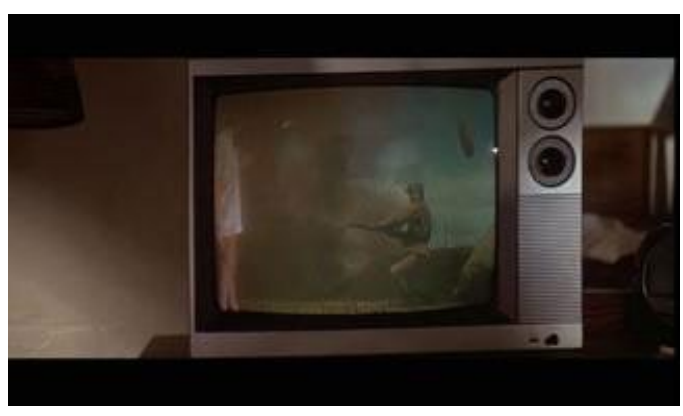

Figura 3. El reflejo de Fabienne, al lado izquierdo de la pantalla de TV, se encuentra inmerso en una balacera.

Fuente: fotograma extraído de la versión en DVD. Todos los derechos pertenecen a la productora Miramax.

La última cita que consideraremos es el tema principal homónimo de Django (Sergio Corbucci, 1966), compuesto por Luis Bacalov, y que escuchamos al inicio de Django desencadenado (Django Unchained, Quentin Tarantino, 2012). De forma parecida a Django, en el western de Tarantino la letra de la canción describe bastante bien el tema y la historia de su filme; versos como «¿Django, siempre has estado solo?», «¿Django, nunca has vuelto a amar?», «Django, ahora tu amor se ha ido», abordan la soledad de Django (Jamie Foxx), la 
separación de su esposa Broomhilda von Shaft, también conocida como Hildi (Kerry Washington), y su devoto amor hacia ella.

En relación con la «alusión», en el cine es cuando se alude a alguna obra (cinematográfica o no) sin citarla. El primer ejemplo es la referencia que hace Tarantino de Juego con la muerte (Game of Death, Robert Clouse, 1978) en Kill Bill vol. 1 (2003); en concreto, Beatrix Kiddo (Uma Thurman) usa un traje similar al de Billy Lo (Bruce Lee), con lo cual, además de hacerse un homenaje a este personaje y, especialmente, a Lee, se acentúan la fuerza y habilidades marciales de Beatrix.

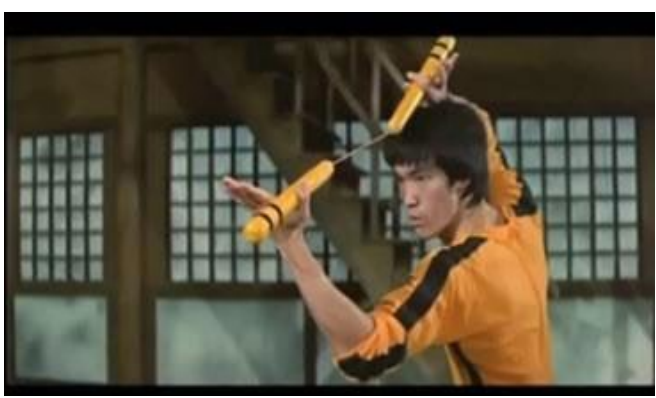

Figura 5. Billy Lo (Bruce Lee) en una escena de acción de Juego con la muerte (1978).

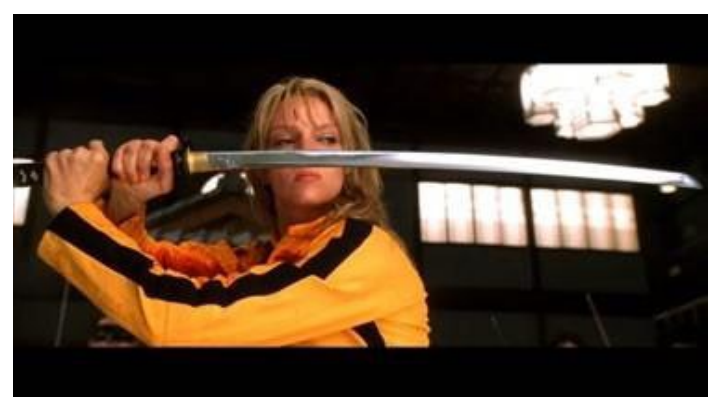

Figura 6. Beatrix Kiddo (Uma Thurman) antes de pelear contra los 88 maníacos en Kill Bill vol.1 (2003).

Fuente: fotograma extraído de la versión de DVD. Todos los de- rechos pertenecen a la productora Miramax.

Fuente: fotograma extraído de la versión de DVD. To- dos

El segundo ejemplo es el flashback de Bastardos sin gloria (Inglourious Basterds, Quentin Tarantino, 2009), en el que Hugo Stiglitz (Til Schweiger) rememora los latigazos que le dieron los nazis durante su encarcelamiento; este hace referencia a otro flashback del western Grupo salvaje (The Wild Bunch, Sam Peckinpah, 1969) en el que Deke Thornton (Robert Ryan) también es azotado. En el caso de Bastardos sin gloria, este flashback acentúa la ira contenida de Hugo.

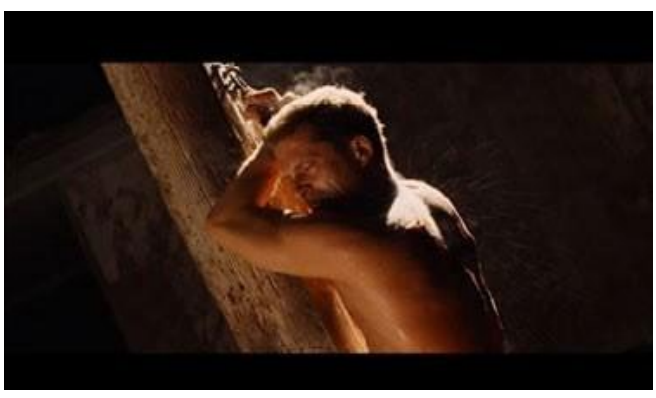

Figura 7. Hugo Stiglitz (Til Schweiger) siendo latigado en Bastardos sin gloria (2009).

Fuente: fotograma extraído de la versión de DVD. Todos los derechos pertenecen a la productora The Weinstein Company.

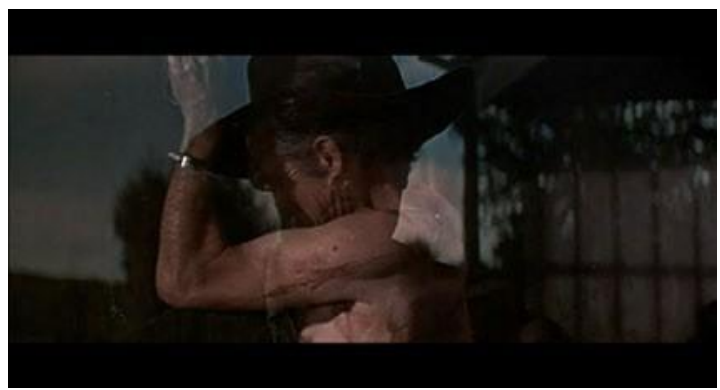

Figura 8. Flashback sobreimpreso de Deke Thornton (Robert Ryan) recibiendo latigazos.

Fuente: fotograma extraído de la versión de DVD. Todos los derechos pertenecen a la productora Warner Bros. 
El último ejemplo está en el cercenamiento de la oreja del policía Marvin Nash (Kirk Baltz), en Perros de reserva (Reservoir Dogs, Quentin Tarantino, 1992), que es una «alusión» del desmembramiento de la oreja de Jonathan (Gino Pernice) en Django. Por supuesto, esta referencia recalca la locura del Sr. Rubio ${ }^{11}$.

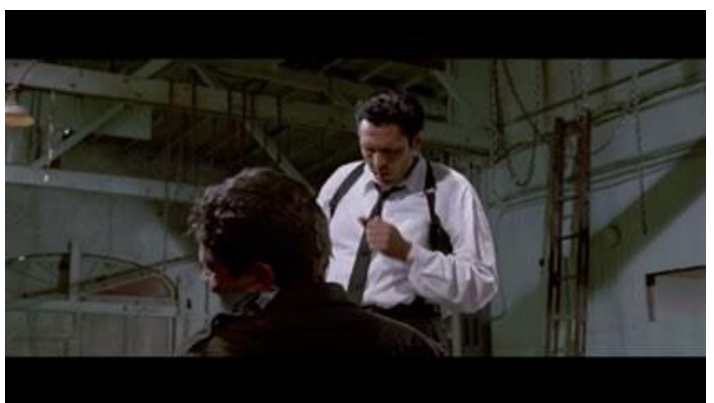

Figura 9. El Sr. Rubio (Michael Madsen) le corta la oreja a Marvin (Kirk Baltz) en Perros de reserva (1992).

Fuente: fotograma extraído de la versión de DVD. Todos los derechos pertenecen a la productora Live Entertainment.

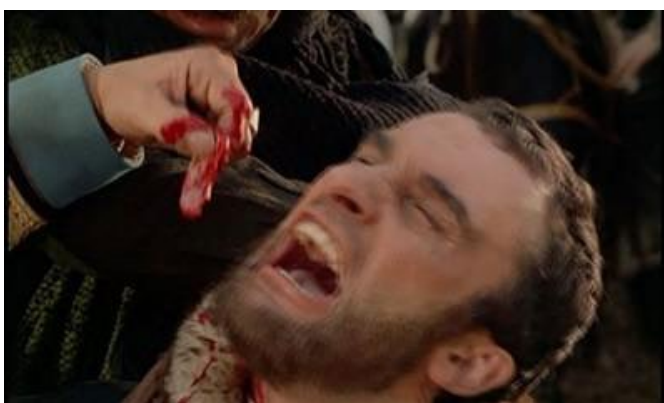

Figura 10. El General Hugo Rodríguez (José Bódalo) cercena la oreja a Jonathan (Gino Pernice) en Django (1966).

Fuente: fotograma extraído de la versión de DVD. Todos los derechos pertenecen a la productora B. R. C. Produzione.

La «paratextualidad», el segundo tipo de «transtextualidad» ya descrito, es en el cine todos aquellos comentarios, grafías, intertítulos, etc., que explican algún detalle particular de un filme. Algunos «paratextos» elementales de la filmografía de Tarantino son: 1) el concepto de literatura pulp que observamos al inicio de Pulp Fiction y sin el cual podría ser enrevesado entender el título y su importancia; 2) las grafías en Había una vez en... Hollywood que muestran las fechas y horas en que se desarrollan algunas escenas ${ }^{12}$; y 3) el comentario del narrador anónimo (Samuel L. Jackson) en Bastardos sin gloria, sobre la alta inflamabilidad de la película de nitrato y la extensa colección de filmes en este formato de Shosanna Dreyfus (Mélanie Laurent), resulta esclarecedor y hasta lúdico para comprender un poco más la escena del incendio del cine de Shosanna.

En cuanto a la «metatextualidad» tenemos que en el cine es cuando uno o varios personajes (o algún otro tipo de instancia diegética o extradiegética, inclusive) hablan de forma crítica sobre alguna obra, sin necesidad de mostrar un extracto visual o sonoro de la misma. En A prueba de muerte (Death Proof, Quentin Tarantino, 2007), Zoë (Zoë Bell), Abernathy

11 De los tres subtipos de «intertextualidad», puntualizados y descritos por Genette, el único que Tarantino no cumple es el plagio. Esto se debe a que, a través de diversas entrevistas, Tarantino ha dejado claro que usa referencias de todas las películas que le gustan. Susana M. Villalba y Miguel Juan Payan (1996) reflexionan sobre si esta especie de juego cinéfilo se debe a una falta de creatividad enorme de Tarantino y, por ende, a un plagio descarado de sus filmes preferidos o, por el contrario, si es una forma de este director de recreación de la memoria y creación pura; ambos concluyen, de forma parecida a Noël Simsolo (2009) y Arturo Serrano (2014), que no existe el plagio en la obra de Tarantino, puesto que este ha dejado claro - de forma táctica o explícita- que las relaciones transtextuales son una parte importante en su estilo autoral, como ya acotamos. Incluso, otros ejemplos parecidos, que sustentan la imposibilidad que existan plagios en la filmografía de un director o una producción que se valen insistentemente de la transtextualidad, son Tim Burton y la serie Los Simpson (The Simpson, Matt Groening, 1989 - present)"

12 Sobre todo, la grafía «Viernes 8 de agosto de 1969 » y las horas de ese día son relevantes, porque advierten al espectador de que la fecha y hora en que la verdadera Sharon Tate fue asesinada, por los miembros de la familia Manson, se acerca. La tragedia real ocurrió en la madrugada del 9 de agosto de 1969. 
(Rosario Dawson), Kim (Tracie Thoms) y Lee (Mary Elizabeth Winstead) valoran positivamente road movies como Vanishing Point (Richard C. Sarafian, 1971) y La indecente Mary y Larry el loco (Dirty Mary Crazy Larry, John Hough, 1974), mientras que denigran el remake 60 segundos (Gone in Sixty Seconds, Dominic Sena, 2000). Más allá de simplemente hablar sobre películas, esta «metatextualidad» nos da pistas sobre los gustos de los personajes, especialmente de Zoë y Kim, además de que introduce el «detonante» de la persecución final, puesto que Zoë les propone conducir un carro similar al del protagonista de Vanishing Point.

Asimismo, en la escena inicial de Perros de reserva, el Sr. Marrón (Quentin Tarantino) analiza el significado real de Like a Virgin (1984) de Madonna, lo cual le confiere una naturalidad inusual al diálogo de los atracadores; y en Habia una vez en... Hollywood, Cliff Booth (Brad Pitt) intenta convencer a Rick Dalton (Leonardo DiCaprio) de que protagonizar spaghetti westerns sería una buena idea para revitalizar su carrera, mientras que Rick denigra en general de las películas de este subgénero.

De manera similar a lo visto en la literatura, la «hipertextualidad» cinematográfica sería de dos tipos. El primero es cuando se establece una relación meramente descriptiva entre un «hipotexto» y su «hipertexto». En Habia una vez en ... Hollywood, Marvin Schwarz (Al Pacino) menciona diversas series de televisión como El Avispón Verde (The Green Hornet, William Beaudine y Leslie H. Martinson, 1966-1967) y Batman (William Dozier, 1966-1968) para ejemplificar cómo estas usaban a actores de cierto renombre para que interpretaran a villanos ocasionales.

A su vez, en Perros de reserva, el Sr. Blanco (Harvey Keitel), el Sr. Rosado (Steve Buscemi), el Sr. Naranja (Tim Roth) y Eddie (Chris Penn) mencionan someramente la serie Get Christie Love! (William A. Graham, 1974-1975) para describir a una camarera llamada Elois; y en este mismo filme, el Sr. Naranja le nombra los cómics de Los 4 fantásticos (Fantastic Four, Stan Lee y Jack Kirby, 1961) a Holdaway (Randy Brooks) para comparar físicamente a Joe Cabot (Lawrence Tierney) con la Cosa.

El segundo subtipo denominado como «transformación» (y también «adaptación»), es cuando una obra (literaria, cinematográfica, etc.) se usa para crear otra. El caso más notorio en la filmografía de Tarantino es Jackie Brown (1997), que es el «hipertexto» de la novela Cóctel explosivo (Rum Punch, 1994), escrita por Elmore Leonard. Esta adaptación es interesante porque, a pesar de adaptar una obra que no escribió, la autoría de Tarantino es notable tanto en la narrativa como en el estilo de su adaptación; además, acerca su versión al subgénero blaxploitation $^{13}$, del cual es admirador. Igualmente, la citada versión de Django, también podría considerarse el «hipotexto» de Django desencadenado, aunque en realidad Tarantino adapta pocos elementos de la de Corbucci.

13 El subgénero blaxploitation se dio a principios de la década de 1970, consistía principalmente en películas policiacas con actores negros como protagonistas, y que buscaban revertir ciertos estereotipos raciales, así como generar empatía hacia la comunidad afroamericana (Monaco, 1979). Grandes exponentes de esta corriente son Las noches rojas de Harlem (Shaft, Gordon Parks, 1971) y Foxy Brown (Jack Hill, 1974). 
La «architextualidad», el último tipo de los descritos por Genette, se refiere en el cine a los títulos de películas que remiten a un género específico. El aludido caso de Pulp Fiction podría considerarse del primer orden, ya que remite al subgénero de la literatura pulp repleto de historias sobre crímenes sorprendentes y que se pueden conectar unas con otras. A su vez, Había una vez en... Hollywood entraría en el tipo que Stam denominó «un filme que reflexiona sobre el propio Hollywood» (2001, p. 155), así como Cantando bajo la lluvia (Singin'in the Rain, Stanley Donen y Gene Kelly, 1952) y Mank (David Fincher, 2020), aunque los títulos de estos filmes no remitan a esa tipología.

Por último, consideraremos las «relaciones transtextuales» desarrolladas por Stam et al. (1999). La «intertextualidad de celebridades» se ejemplifica con los actores Pam Grier, estrella del blaxploitation, David Carradine, otrora ícono de las series de kung-fu, y Franco Nero, referente del western, sobre todo de su subgénero spaghetti western. La elección de estos tres actores para Jackie Brown, los dos volúmenes de Kill Bill y Django desencadenado, respectivamente, no fue casualidad y responde en gran parte al género (o subgénero) en que más se destacaron.

En cuanto a la «intertextualidad genética», el caso más emblemático es Maya Hawke, hija de los actores Uma Thurman y Ethan Hawke, quien actuó en Habia una vez en... Hollywood, y que, por su parecido físico, recuerda enormemente a Thurman. Además, la «intertextualidad genética» también se da en este caso porque Thurman se hizo mundialmente reconocida por su actuación en Pulp Fiction, filme que, según el propio Tarantino, tiene similitudes narrativas con Había una vez en... Hollywood y que, asimismo, contribuyó a la popularidad mediática de Maya Hawke.

Con respecto a la «intratextualidad», en varias de las películas de Tarantino estas se han referido «a sí mismas», mediante la narración de sus personajes o algún narrador extradiegético. Por ejemplo, en Los odiosos ocho (The Hateful Eight, Quentin Tarantino, 2015), luego del asesinato del General Sandford Smithers (Bruce Dern), escuchamos a un narrador (cuya voz la presta el propio Tarantino) describiendo las acciones y posiciones de los personajes en la escenografía, como si se tratara de una obra de teatro; incluso, el narrador apunta que el próximo capítulo del filme se titula «Domergue tiene un secreto». Otro está en Kill Bill vol. 2 (Quentin Tarantino, 2004), en la escena en que Beatrix rememora la matanza en su ensayo de bodas, llegando a mencionar específicamente la historia del filme en sí.

Por otra parte, Tarantino ha utilizado la «autocita» para conectar — de una manera u otra- sus propias películas. En A prueba de muerte, Abernathy usa como tono de celular parte del tema Twisted Nerve (creado por Bernard Herrmann) y que escuchamos en Kill Bill vol. 1 cuando Elle Driver (Daryl Hannah) llega al hospital donde está internada Beatrix; en Bastardos sin gloria, en la segunda escena en que aparecen los Bastardos, escuchamos una parte del tema L'arena (compuesto por Ennio Morricone), y que Tarantino usó en Kill Bill vol. 2, concretamente en la escena en que Beatrix escapa de su tumba; y refiriéndonos a este filme, al inicio vemos un fragmento de la escena en que Bill le dispara a Beatrix en la cabeza en Kill Bill vol. 1. 
Finalmente, en cuanto a la «intertextualidad falsa», Tarantino ha creado diversas películas y series falsas para incluirlas dentro de su obra. La primera es la película propagandística nazi El orgullo de la nación (supuestamente producida por Joseph Goebbels) y que tiene gran relevancia dentro de Bastardos sin gloria; otros ejemplos son la serie western La ley de la recompensa, la película de espías Operazione Dyn-O-Mite! y los westerns cinematográficos Nebraska Jim, Mátame ahora Ringo, dijo el Gringo y Sangre roja, piel roja, todas protagonizadas por Rick Dalton en la diégesis de Había una vez en... Hollywood. Incluir películas falsas dentro de su filmografía, le permite a Tarantino ahondar en la historia de sus películas y personajes, además de que experimenta con el estilo cinematográfico de filmes de alguna década específica (sobre todo con las producciones ficticias en Habia una vez en ... Hollywood y la década de 1960).

\section{Conclusión}

La «transtextualidad», expuesta por Gérard Genette, y que parte a su vez del «dialogismo» de Mijaíl Bajtín y la «intertextualidad» de Julia Kristeva, conforma un amplio campo teórico de inestimable relevancia dentro de los estudios literarios y del arte en general. Incluso, el postulado de Genette es más amplio y específico en las distintas formas de «transtextualidad», que los de sus antecesores. Además, la ampliación de esta teoría hecha por Robert Stam, Robert Burgoyne y Sandy Flitterman-Lewis, para los estudios del cine, demuestra su posible adaptación a otras formas de arte e importancia.

Por lo tanto, debido a las similitudes prácticas y teóricas entre la literatura y el cine, aplicamos los axiomas de la «transtextualidad» a la filmografía de Quentin Tarantino, director actualmente destacado en el ejercicio transtextual, para analizar cómo desarrolla varios aspectos de sus temáticas, narrativas y estilo a partir de las muchas e insistentes relaciones transtextuales que hace.

Principalmente utiliza la «cita» para tratar la historia de sus personajes, «advertir»al espectador de algún conflicto próximo, profundizar en el tema de sus filmes, entre otros usos. «La alusión» funciona para acentuar alguna característica psicológica o física de sus personajes, pero de manera velada y hasta en forma de homenaje. Debemos acotar que estos dos tipos de «transtextualidad» son los más empleados por Tarantino en toda su filmografía.

Las demás categorías de «transtextualidad», también relevantes en su trabajo, son: la «paratextualidad», empleada para explicar aspectos de sus tramas de manera lúdica y diferente, como es el caso de las diversas grafías explicativas y los comentarios de los narradores; la «metatextualidad», utilizada no solo para expresar sus preferencias cinéfilas, sino también para tratar algún personaje o hecho dentro de la diégesis, puesto que en las críticas de películas y series televisivas que hacen sus personajes, estos «insinúan» acontecimientos futuros en la diégesis; la «hipertextualidad», aprovechada para tomar uno o varios textos (películas, novelas, etc.) ya existentes y transformarlos a su conveniencia; y la «architextualidad» que utiliza para relacionar los títulos de sus filmes con diversos géneros literarios y cinematográficos. 
Asimismo, utiliza en mayor o menor medida los cinco tipos de formas transtextuales de Stam et al. (1999): «intertextualidad de celebridades», «intertextualidad genética», «intratextualidad», «autocita» e «intertextualidad falsa». De estos, los más relevantes para nuestra investigación son los últimos tres mencionados, ya que acentúan la forma más personal de su escritura, dirección y del universo cinematográfico que construyó. Igualmente, crear producciones falsas y utilizarlas en algunas de sus obras, le permite a Tarantino enriquecer sus historias y experimentar con otros estilos y géneros.

Todo lo anterior comprueba la inmensa cantidad de relaciones transtextuales elaboradas por Tarantino; la importancia de esta práctica que expone sus preferencias relativas al cine, las series de televisión y hasta de la literatura, y, más importante aún, cómo le es útil para desarrollar parte de su estilo autoral, dándole tanta relevancia a lo expuesto como a la violencia gráfica, la construcción de los diálogos, la hibridación de géneros, entre otras características; y, por último, la mencionada reciprocidad entre los estudios literarios y el cine, así como su propia pertinencia.

\section{Referencias}

Bajtín, Mijaíl. Problemas de la poética de Dostoievski (2.a ed.). México, Fondo de Cultura Económica, 2005.

Cabrera Infante, Guillermo. Cine o sardina (2.a ed.). Madrid, Editorial Alfaguara, 1997.

Coetzee, J. M. Mecanismos internos. Ensayos 2000-2005. Barcelona, Random House Mondadori, 2009.

Colbert, David. Los mundos mágicos de El señor de los anillos. Barcelona, Ediciones B, 2003.

Dumont, Gabriel. Beatrix Kiddo en el viejo Oeste. Influencia narrativa, estilística y transtextual del western en los filmes Kill Bill vol. 1 y Kill Bill vol. 2 (tesis de pregrado, Universidad Central de Venezuela, Caracas), 2017. Recuperado de http://saber.ucv. $\mathrm{ve} /$ handle/10872/20886

García, Narcisa. Hello, Wall-e: la citación intertextual (tesis de pregrado, Universidad Central de Venezuela, Caracas), 2011.

Genette, Gerard. Palimpsestos. La literatura en segundo grado. Madrid, Editorial Taurus, 1989. 
Gubern, Román. y Prat, Joan. Las raíces del miedo. Antropología del cine de terror. Barcelona, Tusquets Editores, 1979.

Kennedy Toole, John. La conjura de los necios (44.a ed.). España, Editorial Anagrama, 2011.

Kernan, Alvin. La muerte de la literatura. Caracas, Monte Ávila Editores Latinoamericana, 1996.

Kristeva, Julia. Semiótica I. Madrid, Editorial Fundamentos, 1981.

Kristeva, Julia. Bajtín, la palabra, el diálogo y la novela. En Navarro, Desiderio (ed.). Intertextua-lité. Francia en el origen de un término y el desarrollo de un concepto (pp. 1-24). La Habana: UNEAC - Casa de las Américas - Embajada de Francia en Cuba, 1997.

Leonard, Elmore. Cóctel explosivo. Barcelona, Ediciones B, 1994.

Milton, John. El paraíso perdido. Barcelona, Editorial Ramón Sopena, 1975.

Monaco, James. American Film Now. The people, the power, the money, the movies. Nue- va York: The New American Library, 1979.

Orwell, George. 1984. Bogotá, Editorial Planeta, 2012.

Posteguillo, Santiago. La sangre de los libros. Barcelona, Editorial Planeta, 2015.

Romaguera i Ramió, Alsina Thevenet, eds. Textos y manifiestos del cine. Estética. Escuelas. Movimientos. Disciplinas. Innovaciones. Madrid, Ediciones Cá- tedra, 1993.

Sábato, Ernesto. El túnel. Barcelona, Editorial Seix Barral, 2007.

Schwanitz, Dietrich. La cultura. Todo lo que hay que saber. Madrid, Editorial Taurus, 2003.

Serrano, Arturo. El cine de Quentin Tarantino. Una aproximación a la estética de la violencia. Caracas, Editorial Publicaciones UCAB, 2014.

Shelley, Mary. Frankenstein o el moderno Prometeo (2.a ed.). Barcelona, Random House Mondadori, 2011.

Simsolo, Noël. El cine negro. Madrid, Alianza Editorial, 2009.

Stam, Robert. Teorías del cine. Barcelona, Ediciones Paidós Ibérica, 2001. 
Stam, Robert, Burgoyne, Robert, y Flitterman-Lewis, Sandy. Nuevos conceptos de la teoría del cine: estructuralismo, semiótica, narratología, psicoanálisis, intertextualidad. Barcelona, Editorial Paidós Ibérica, 1999.

Steiner, Jean-Françoise. Treblinka. Barcelona, Editorial Plaza \& Janes, 1973.

Tarantino, Quentin. Malditos bastardos. Barcelona, Random House Mondadori, 2009.

Villalba, Susana M., y Payán, Juan Miguel. Guía del cine independiente americano de los 90. Madrid, Nuer Ediciones, 1996.

Villalobos Alpízar, Iván. "La noción de intertextualidad en Kristeva y Barthes”. Revista de Filosofia de la Universidad de Costa Rica, 41(103), 2003, págs. 137-146. Web.

\section{Filmografía}

A prueba de muerte. Dir. Quentin Tarantino. The Weinstein Company, 2007. DVD.

Perros de reserva. Dir. Quentin Tarantino. Live Entertainment - Dog Eat Dog Productions, 1992. DVD.

Pulp Fiction. Dir. Quentin Tarantino. A Band Apart - Jersey Films - Miramax, 1994. DVD.

Jackie Brown. Dir. Quentin Tarantino. A Band Apart-Miramax, 1997. DVD.

Kill Bill volumen 1. Dir. Quentin Tarantino. A Band Apart - Miramax, 2003. DVD.

Kill Bill volumen 2. Dir. Quentin Tarantino. A Band Apart - Miramax, 2004. DVD.

Bastardos sin gloria. Dir. Quentin Tarantino. Universal Pictures - A Band Apart - The Weinstein Company - Visiona Romántica - Zehnte Babelsberg, 2004. DVD.

Mank. Dir. David Fincher. Netflix, 2020.

Juego con la muerte. Dir. Robert Clouse. Golden Harvest - Columbia Pictures, 1978. DVD.

Django. Dir. Sergio Corbucci. B. R. C. Produzione - Tecisa, 1966. DVD.

Foxy Brown. Dir. Jack Hill. American International Pictures, 1974. DVD. 
Grupo salvaje. Dir. Sam Peckinpah. Seven Arts - Warner Bros, 1969. DVD.

Cantando bajo la lluvia. Dir Gene Kelly, Stanley Donen. Metro-Goldwyn-Mayer, 1952. DVD.

Las noches rojas de Harlem. Dir. Gordon Parks. Metro-Goldwyn-Meyer, 1971. DVD.

Los odiosos ocho. Dir. Quentin Tarantino. Double Feature Films - FimColony - The Weinstein Company, 2015. DVD.

Habia una vez en ... Hollywood. Dir. Quentin Tarantino. Columbia Pictures - Heyday Films

- Bona Film Group, 2019. DVD.

Django desencadenado. Dir. Quentin Tarantino. A Ban Apart - Columbia Pictures - The Weinstein Company, 2012. DVD.

Creepshow: El festín del terror. Dir. George Romero. Laurel-Show Inc - United Film Distribu- tion Compay - Creepshow Films Inc, 1982. DVD.

Cementerio de mascotas. Dir. Mary Lambert. Paramount Pictures, 1989. DVD.

Los Simpson. Dir. Matt Groening. Estados Unidos: Gracie Films - 20th Century Fox, 1989-presente. DVD. 